University of Nebraska - Lincoln

DigitalCommons@University of Nebraska - Lincoln

2001

\title{
Evaluation of an Algorithm for Predicting Albedo in Heliotropic Crops
}

Elizabeth A. Walter-Shea

University of Nebraska - Lincoln, ewalter-shea1@unl.edu

A. WEISS

University of Nebraska - Lincoln, aweiss1@unl.edu

Follow this and additional works at: https://digitalcommons.unl.edu/natrespapers

Part of the Natural Resources and Conservation Commons, Natural Resources Management and Policy Commons, and the Other Environmental Sciences Commons

Walter-Shea, Elizabeth A. and WEISS, A., "Evaluation of an Algorithm for Predicting Albedo in Heliotropic Crops" (2001). Papers in Natural Resources. 1176.

https://digitalcommons.unl.edu/natrespapers/1176

This Article is brought to you for free and open access by the Natural Resources, School of at DigitalCommons@University of Nebraska - Lincoln. It has been accepted for inclusion in Papers in Natural Resources by an authorized administrator of DigitalCommons@University of Nebraska - Lincoln. 


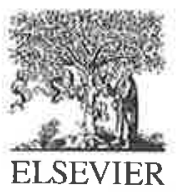

AGRICULTURAL

SYSTEMS

Agricultural Systems 68 (2001) 137-150

www.elsevier.com/locate/agsy

\title{
Evaluation of an algorithm for predicting albedo in heliotropic crops 2 s
}

\author{
A. Weiss ${ }^{a, *}$, T.J. Arkebauer ${ }^{b}$, E.A. Walter-Shea ${ }^{a}$ \\ ${ }^{a}$ School of Natural Resource Sciences, University of Nebraska-Lincoln, Lincoln, NE 68583-0728, USA \\ ${ }^{\mathrm{b}}$ Department of Agronomy, University of Nebraska-Lincoln, Lincoln, NE 68583-0817, USA
}

Received 6 July 2000; received in revised form 15 December 2000; accepted 21 December 2000

\begin{abstract}
Albedo (the fraction of reflected incoming solar radiation in the 400-3000 nm range) is of critical importance in crop simulation studies because it determines how much solar radiation is available for carbon uptake, crop water use, and ultimately productivity and yield. However, many crop simulation models do not place as much emphasis on albedo as is warranted given its importance in determining these crop processes. In addition, prediction of albedo in crop simulation models dealing with heliotropic crops (their leaves follow the sun) has received relatively little attention. An albedo algorithm based on a spherical leaf angle distribution was modified to predict albedo in two heliotropic crops, alfalfa (Medicago sativa L.) and soybean (Glycine $\max (\mathrm{L}$.) Merr.). Since no analytical expression exists for the heliotropic leaf angle distribution, linear relationships were developed to predict the albedo of these heliotropic crops from the albedo of a crop with a spherical leaf angle distribution. These relationships were developed from field data and tested on independent field measurements. Albedo was measured over soybean for a wide range of leaf area indices and leaf optical properties and between two cuttings in alfalfa. The normalized mean absolute error was used to compare predicted and measured values. There was good agreement between predicted and measured values except under foggy conditions when the direct beam fraction was zero and when water droplets on leaf surfaces may have influenced leaf optical properties. (C) 2001 Elsevier Science Ltd. All rights reserved.
\end{abstract}

Keywords: Albedo; Heliotropic; Alfalfa; Soybean

is Published as Paper No. 12767, Journal Series, Nebraska Agricultural Research Division

* Corresponding author. Tel.: +1-402-472-6761; fax: + 1-402-472-6614.

E-mail address: aweiss1@unl.edu (A. Weiss).

0308-521X/01/\$ - see front matter (C) 2001 Elsevier Science Ltd. All rights reserved.

PII: S0308-521X(01)00004-X 


\section{Introduction}

Crop simulation models are comprised of various algorithms that predict important processes such as net canopy photosynthesis, transpiration, soil evaporation, dry matter accumulation, and canopy development. An important, but often underappreciated component in these models is albedo; the fraction of incoming solar radiation in the $400-3000 \mathrm{~nm}$ range that is reflected from the crop canopy and soil surface. Albedo is of critical importance because it determines how much solar energy is available for carbon uptake, crop water use; and ultimately productivity and yield. Canopy albedo can be predicted from a knowledge of leaf optical properties and their arrangement in the crop canopy. This quantity has been investigated from several perspectives, e.g. analytically (Unkasevic, 1989), utilizing satellite data (Dedieu et al., 1987), and in the applied situation of irrigation scheduling (Dvoracek and Hannabas, 1990).

Several important field crops, such as alfalfa (Medicago sativa L.) and soybean (Glycine max (L.) Merr.), are heliotropic, i.e. their leaves follow the sun. This response implies that the leaf angle distribution changes throughout the day adding additional complexity to the calculation of canopy albedo. Our need was for a relatively simple method to calculate albedo on an hourly basis for these two crops for use in several modeling applications. Goudriaan (1977) published an algorithm for predicting albedo from canopies with spherical leaf angle distributions. Jacobs and van Pul (1990) validated the albedo algorithm of Goudriaan (1977), using two seasons of data collected over a (non-heliotropic) maize (Zea mays L.) crop. The objective of this study was to: (1) extend the original algorithm of Goudriaan (1977) to these two widely grown crops with heliotropic leaf angle distributions; and (2) verify the results from the new algorithm using independent data sets over a range of leaf area indices and (for soybean) a range of leaf optical properties.

\section{Materials and methods}

\subsection{Original algorithm}

This section begins with a discussion of the original algorithm which is applicable to a spherical leaf angle distribution. A spherical leaf angle distribution means that the angular distribution of leaves in the canopy is similar to the angular distribution of small surface areas on a sphere. The spherical leaf angle distribution is common in many plant canopies (e.g. maize) and implies that the leaf area projected in the view direction is invariant with view angle.

A discussion of the experimental data collected for use in modifying the original algorithm follows. Next the independent data sets used for model evaluation and the procedures associated with this evaluation are discussed.

An overview of the original algorithm (Goudriaan, 1977) follows; more details are given in Jacobs and van Pul (1990). This algorithm first calculates the albedo of a canopy comprised of horizontal leaves by assigning different leaf transmission 
and reflection properties for the photosynthetically active (PAR; 400-700 $\mathrm{nm}$ ) and the near infrared (NIR; 700-3000 $\mathrm{nm}$ ) radiation bands, taking into account the leaf area index (LAI) and soil surface albedo. This horizontal value is next adjusted to account for a spherical leaf angle distribution considering both direct beam and diffuse radiation components (see Appendix for a list of variable definitions).

For horizontal leaves, the albedo $\left(A_{\mathrm{HOR}}\right)$ is given by Eqs. (1)-(3):

$$
A_{\mathrm{HOR}}=\frac{A^{\prime}\left(1-A^{\prime} A_{\mathrm{s}}\right)-\left(A^{\prime}-A_{\mathrm{s}}\right) \exp (-2 a \mathrm{LAI})}{1-A^{\prime} A_{\mathrm{s}}-A^{\prime}\left(A^{\prime}-A_{\mathrm{s}}\right) \exp (-2 a \mathrm{LAI})}
$$

where: $A_{\mathrm{s}}=$ albedo of soil surface; $a=$ extinction coefficient; $A^{\prime}=$ limit of albedo as LAI becomes very large; and LAI = leaf area index.

$$
a^{2}=\left[(1-\mathrm{TL})^{2}-\mathrm{AL}^{2}\right]
$$

where: $\mathrm{AL}=$ leaf reflectivity; and $\mathrm{TL}=$ leaf transmissivity.

$$
A^{\prime}=\mathrm{AL}(1-\mathrm{TL}+a)^{-1}
$$

By assuming equal contributions from the PAR and NIR bands, a first estimate of the albedo from incoming solar irradiance $\left(A_{\mathrm{SOL}}\right)$ is given by:

$$
A_{\mathrm{SOL}}=0.5 A_{\mathrm{HOR}}(\mathrm{PAR})+0.5 A_{\mathrm{HOR}}(\mathrm{NIR})
$$

For a spherical leaf angle distribution, the direct $\left(A_{\mathrm{DIR}}\right)$ and diffuse $\left(A_{\mathrm{DIF}}\right)$ correction to this estimate of the albedo is given by:

$$
A_{\mathrm{DIR}}=A_{\mathrm{SOL}}\left(\frac{2}{1+1.6 \sin h}\right)
$$

where $h=$ solar elevation angle (degrees) and

$$
A_{\mathrm{DIF}}=A_{\mathrm{SOL}} \frac{2}{1+1.6 \sin \left(30^{\circ}\right)}=1.11 A_{\mathrm{SOL}}
$$

The calculation of $A_{\mathrm{DIF}}$ assumes that the diffuse sky radiation is isotropic and can be estimated by a single direct beam at an elevation angle of $30^{\circ}$. The albedo of the canopy $\left(A_{\mathrm{CPY}}\right)$ is then given by:

$$
A_{\mathrm{CPY}}=f A_{\mathrm{DIR}}+(1-f) A_{\mathrm{DIF}}
$$

where $f$ is the direct beam fraction of the incoming solar radiation. 


\subsection{Experimental data}

Data used in this study were collected as part of two independent experiments. One experiment was conducted in soybean grown at the East Campus of the University of Nebraska-Lincoln $\left(40^{\circ} 46^{\prime} \mathrm{N}, 96^{\circ} 39^{\prime} \mathrm{W}\right.$, elevation $\left.383 \mathrm{~m}\right)$ in 1992 (WalterShea, 1993); albedo was measured for clear sky conditions only during the period from 15 July (DOY 197) to 27 September (DOY 271). The other experiment was conducted in alfalfa at the University of Nebraska Agricultural Research and Development Center near Mead, NE $\left(41^{\circ} 09^{\prime} \mathrm{N}, 96^{\circ} 30^{\prime} \mathrm{W}\right.$, elevation $\left.354 \mathrm{~m}\right)$ in 1994; albedo was measured over five regrowth cycles from May (DOY 122) through October (DOY 297; Walter-Shea et al., 1997). The soil type at both locations was a Sharpsburg silty clay loam (fine montmorillonitic, mesic Typic Argiudoll).

In both experiments incoming and reflected solar irradiance were measured with Eppley Precision Spectral Pyranometers (model PSP, the Eppley Laboratory, Inc., Newport, RI) and were sampled every $10 \mathrm{~s}$. The albedo data were summarized into $15 \mathrm{~min}$ averages from which hourly averages centered on the hour (e.g. the period $1130-1230$ was represented by 1200) were formed. Data from DOY 225-271 were used in this analysis. Intermittent problems with the data loggers in the 1992 soybean experiment were not completely resolved until DOY 240; spurious data prior to this date have been eliminated from the analysis. A subset of the alfalfa data, from the second and third regrowth cycles DOY 157-DOY 206, were analyzed. It was assumed that this subset would be representative of a wide range of LAI conditions in alfalfa. Measured and simulated albedo values used in this analysis began when the elevation angle was approximately $26^{\circ}$ on DOY 157 and $24^{\circ}$ on DOY 206. Maximum elevation angles on these dates were $71^{\circ}$ and $61^{\circ}$, respectively.

Spectral responses of the reflectance and transmittance of the abaxial and adaxial surfaces of soybean and alfalfa leaflets were measured with a spectroradiometer (model SE-590, Spectron Engineering, Denver, CO) in conjunction with an integrating sphere (model 1800-12, Li-Cor Inc., Lincoln, NE). The SE-590 measures spectral radiation in the $400-1100 \mathrm{~nm}$ region in narrow bands $(\sim 3 \mathrm{~nm})$. The narrow band responses were integrated to obtain leaflet PAR $(400-700 \mathrm{~nm})$ and NIR $(700-1100 \mathrm{~nm}$ ) reflectance and transmittance properties, (AL and TL, respectively used in Eqs. (2) and (3) to calculate $a$ and $A^{\prime}$ ). [It was assumed that the NIR properties in the measured region $(700-1100 \mathrm{~nm})$ were the same as those in the entire region (700-3000 nm).] Optical properties were measured on eight soybean leaflets on 15 July (DOY 197), 28 July (DOY 210), 12 August (DOY 225), 25 August (DOY 238), 30 August (DOY 243), 11 September (DOY 255), 21 September (DOY 265), and 29 September (DOY 273). The transmittance and reflectance responses of the PAR and NIR regions for soybean are illustrated in Fig. 1a, b. A different fifth order polynomial for each property was fitted through the average of the abaxial and adaxial surfaces, all $r^{2}>0.99$. Leaf optical properties of alfalfa were determined from 40 alfalfa leaflets on DOY 268 in 1990 using the model SE590 spectroradiometer and integrating sphere (Cornell, 1991). For alfalfa, AL and TL in the PAR were 0.127 and 0.0345 ; and in the NIR band were 0.44 and 0.44 , respectively. 


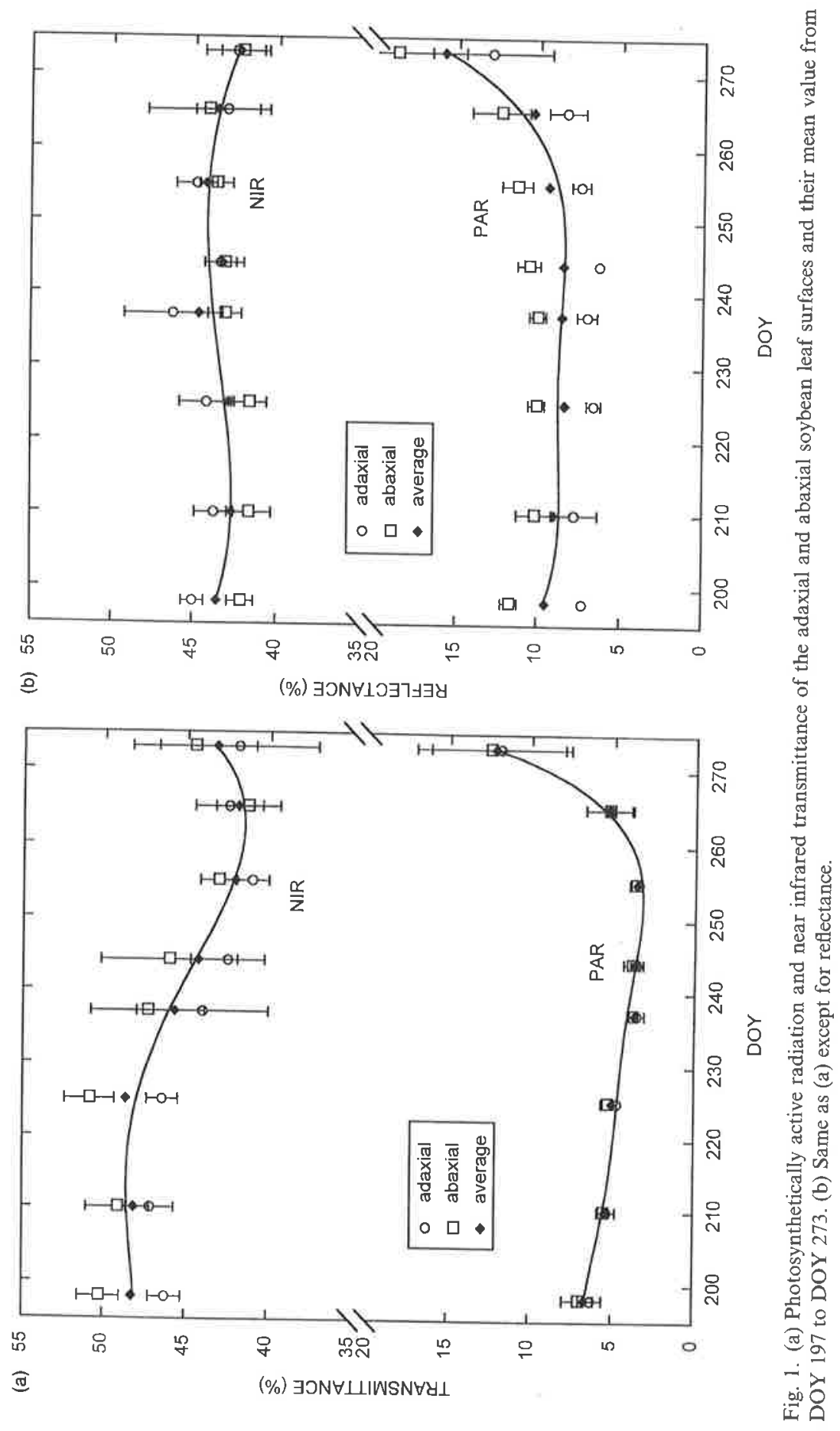


LAI was estimated indirectly (model LAI-2000 Plant Canopy Analyzer, Li-Cor, Lincoln, NE). Soybean LAI was estimated 14 times during the growing season and daily values were estimated using a fourth order polynomial $\left(r^{2}=0.99\right)$. The alfalfa LAI was estimated six and seven times during the second and third regrowth cycles and daily LAI values were estimated for each data set using different fourth order polynomials (all $r^{2}=0.99$ ).

\subsection{Modification of the original algorithm}

Soybean and alfalfa are heliotropic plants (Meyer and Walker, 1981; Moran et al., 1989). There are no analytically derived expressions to adjust albedo estimates for horizontal leaf angle distributions to heliotropic distributions as there are for spherical leaf angle distributions (Goudriaan, personal communication). When the measured alfalfa albedo values for DOY 177 were compared to the modeled albedo using Eq. (7), both curves followed the same diurnal pattern except there was a consistent displacement between the two curves (Fig. 2). DOY 177 was a sunny day, with complete canopy closure, $\mathrm{LAI}=4.2$. Similar observations were noted in soybean for DOY 217,242 , and 259 , average LAI was 4.8 . To account for the heliotropism, a linear relationship between the albedo from the modeled spherical distribution, as the dependent variable, and the measured albedo from the alfalfa and soybean, as independent variables (for these dates DOY 177 for alfalfa; DOY 217, 242 and 259 for soybean) was used to predict albedo of these heliotropic crops. These relationships for soybean and alfalfa were:

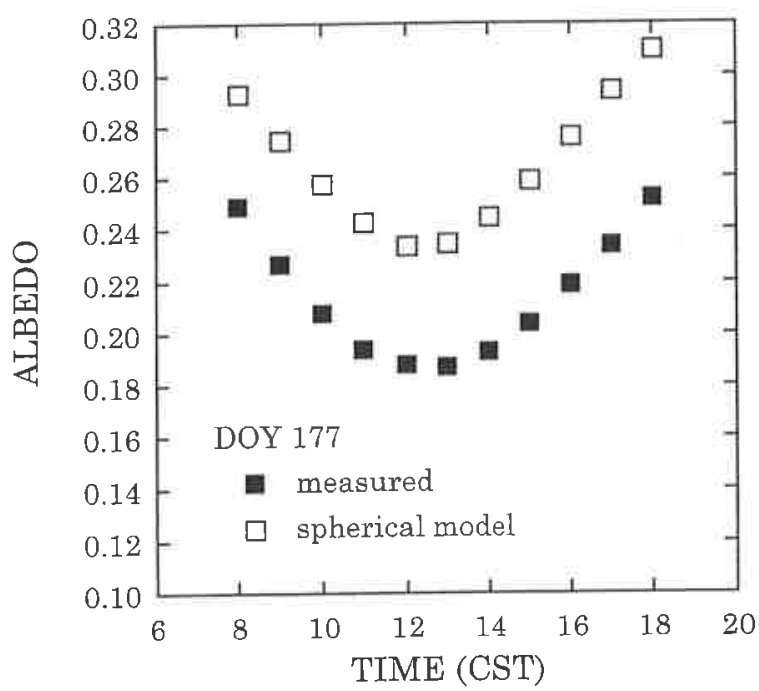

Fig. 2. Comparison of measured alfalfa albedo for DOY 177 with predictions from original model (Eqs. (1)-(7)). 
$A_{\mathrm{SOY}}=0.9646 A_{\mathrm{CPY}}-0.0253$

$r^{2}=0.92$,

and

$$
\begin{aligned}
& A_{\mathrm{ALF}}=0.9008 A_{\mathrm{CPY}}-0.0252 \\
& r^{2}=0.96 .
\end{aligned}
$$

The intercepts of these relationships are almost identical; data from other heliotropic crops are not available to determine if a family of curves exist with the same intercepts and different slopes or if these are fortuitous results. The data used to develop these relationships (Eqs. (8) and (9)) were not used in the analyses of model predictions. Daily albedo values were calculated as the mean of the hourly values. This method of calculation weighs each hourly value equally and does not give more weight to the hours of larger solar irradiance.

Soil albedo $\left(A_{s}\right)$ was estimated from measurements made immediately after each of four alfalfa regrowth cycles under dry and wet conditions. Since soil albedo was not measured directly the following approach was used to estimate this parameter. If more than $5 \mathrm{~mm}$ of precipitation fell the day before the albedo was measured, the soil was considered wet, and thus this albedo represented wet soil conditions. Changes in soil albedo as the soil dried were estimated by assuming there was a linear change in soil albedo from wet to dry values over a 5-day period. Values of soil albedo varied from 0.15 to 0.20 . The direct beam fraction $(f)$ was calculated using the algorithms given in Weiss and Norman (1985). The solar elevation angle was determined from procedures in Duffett-Smith (1990).

\subsection{Evaluation}

The normalized mean absolute error (NMAE) was used to compare measured $(M)$ and predicted $(P)$ albedo values from Eqs. (8) and (9) (Janssen and Heuberger, 1995), i.e. the mean absolute error, MAE, was scaled by the mean measured value $\bar{M}$ :

$$
\mathrm{NMAE}=\frac{\mathrm{MAE}}{\bar{M}}
$$

The MAE was calculated as:

$$
\mathrm{MAE}=\frac{\sum_{i=1}^{n}\left|P_{i}-M_{i}\right|}{n}
$$

where $n$ is the number of observations. Obviously, the closer the NMAE is to zero, the closer is the prediction to the measured value. This statistical measure is not as sensitive to outliers as the root mean square error and since an absolute value is taken, positive and negative differences between predicted and measured values can not compensate for each other as in the calculation of the average error (which is similar 
to Eq. (11) except for the absolute value signs). Average NMAE was calculated as the average of the hourly or daily NMAE values.

\section{Results and discussion}

Comparisons of measured and predicted albedos for soybean over a range of LAIs (5.67-2.45), from peak growth through early senescence are given in Fig. 3 for DOY 225-272 (excluding data used to develop Eqs. (8) and (9)). This period also includes substantial changes in soybean leaf optical properties (Fig. 1a, b). On DOY 225 there was good agreement $(\mathrm{NMAE}=0.04)$ between measured and predicted albedo values in the late morning and early afternoon hours. There were greater differences between these values in the early morning and late afternoon which were probably related to measurement difficulties already noted. There was good agreement between measured and predicted albedo values on DOY 253, 263, and 272 (NMAE $=0.051,0.042$, and 0.029 , respectively). Between these last two days the model captured the albedo differences which resulted from relatively large differences in leaf PAR reflectance and transmittance. The leaf NIR optical properties did not change dramatically during this period. These results indicate that the model performs well for a wide range of LAIs and leaf optical properties.

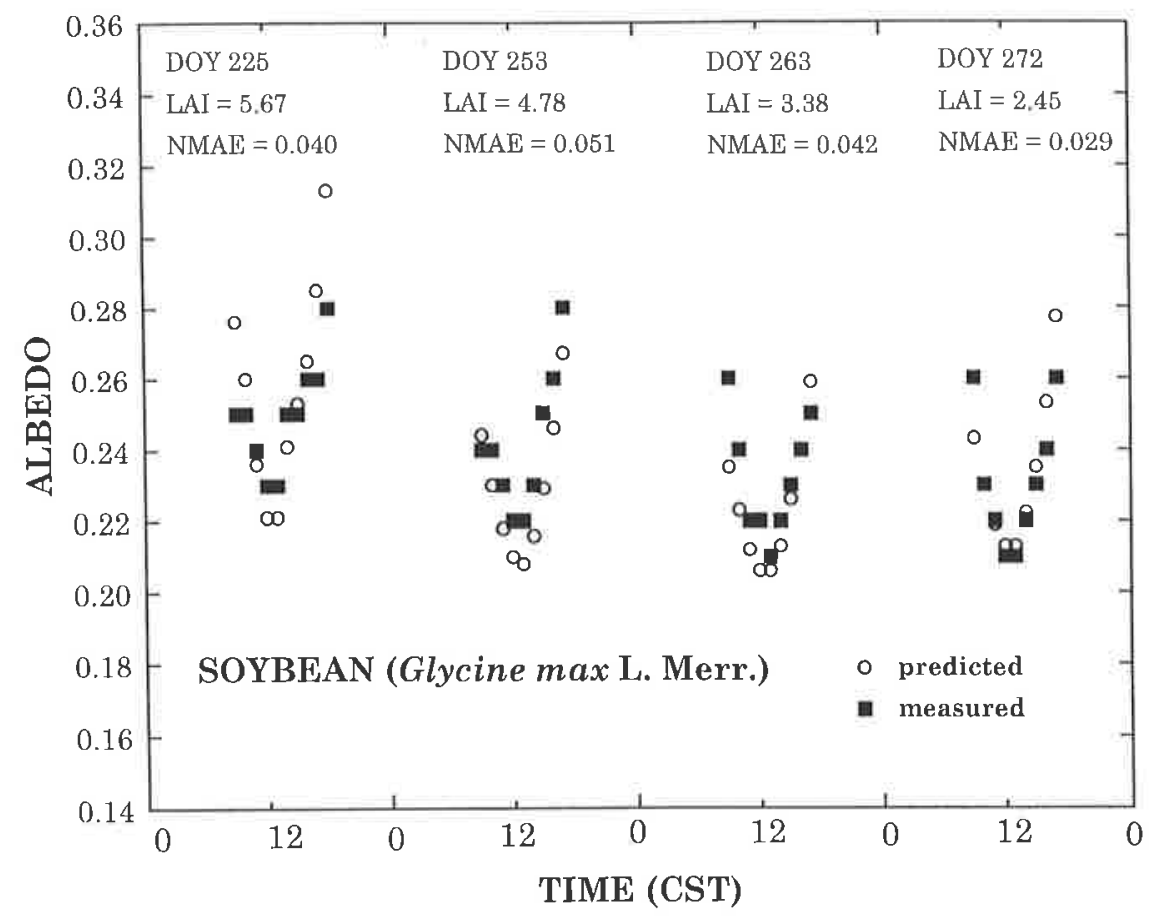

Fig. 3. Comparison between predicted and measured hourly albedo values over soybean for DOY 225, 253,263 , and 272 . 
A representative sample of the distribution of hourly values of albedo of alfalfa for four LAIs are given in Fig. 4 for the two regrowth cycles. As LAI increased, the distributions were displaced toward higher values of albedo, i.e. the canopy reflectance increased. In general, there was good agreement between measured and

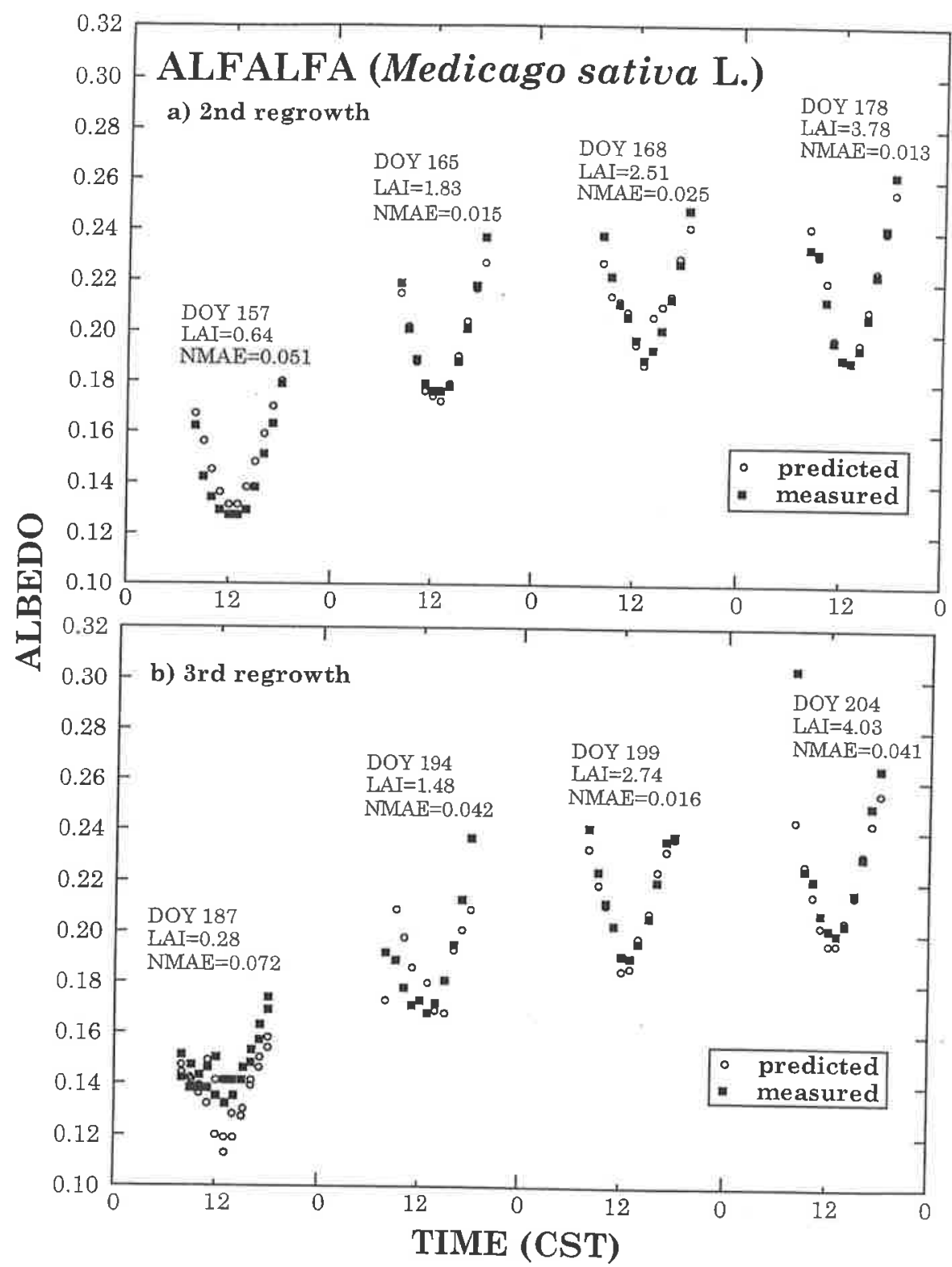

Fig. 4. Distribution of hourly values of albedo over alfalfa for four representative days during each of the two regrowth cycles. 
predicted albedo values for alfalfa. For the first period, the NMAE varied from 0.051 (DOY 157) to 0.013 (DOY 178) while there was more variability in this statistic for the second regrowth cycle, ranging from 0.016 (DOY 199) to 0.072 (DOY 187). Thus data from alfalfa also support the applicability of the model to a range of LAIs.

There was good agreement $(\mathrm{NMAE}=0.045)$ between measured and predicted daily values of alfalfa albedo, Fig. 5. When the LAI was greater than 1.0, the albedo varied from 0.17 to 0.25 . Predictions were closer to measured values during this period and rain did not appear to influence predictions. In contrast, when the LAI was less than 1.0, there was more scatter in the data, and no consistency in predictions between regrowth cycles 2 and 3. Reasons for this behavior will be discussed subsequently.

The distribution of NMAE based on daily alfalfa albedo values (calculated from hourly values) for the two regrowth cycles is given in Fig. 6. The largest values of the NMAE during the first period occurred during DOY 157-160 and are attributed to periods of fog and overcast sky conditions alternating with periods of sunny and partly cloudy skies. During foggy and overcast periods hourly values of incoming

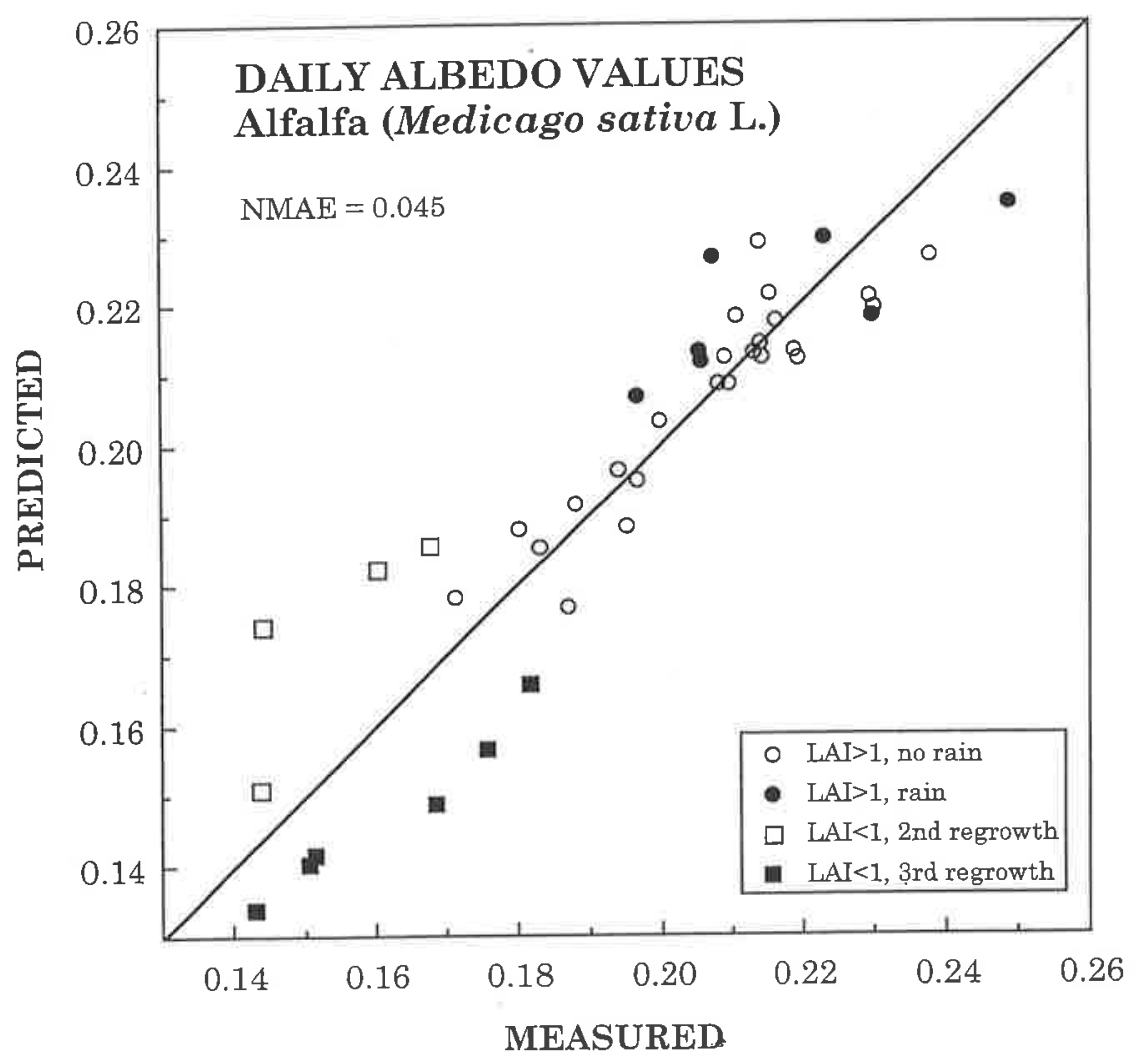

Fig. 5. Measured versus predicted daily alfalfa albedo values for all days during both regrowth cycles, excluding the day used for calibration purposes. 


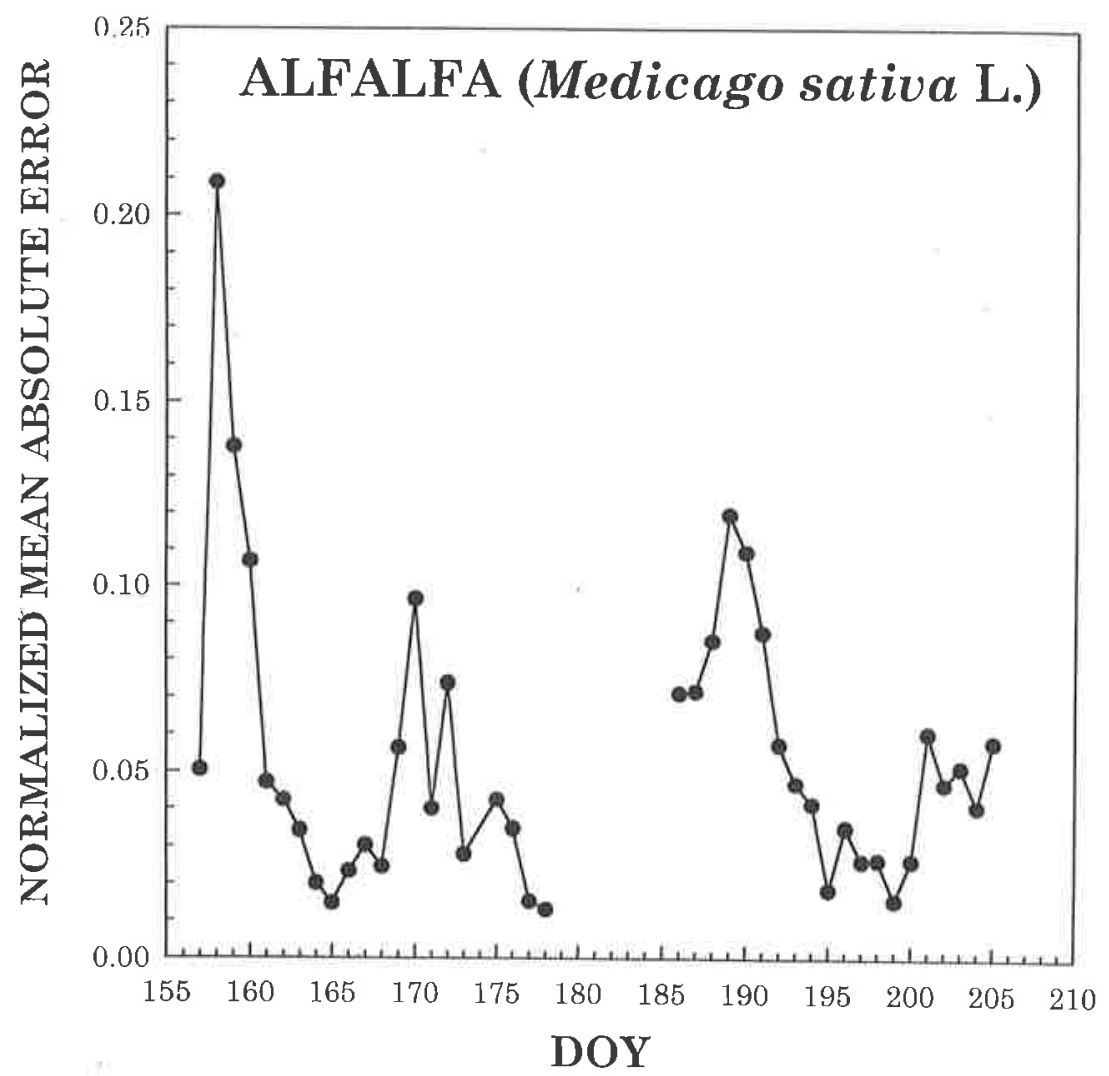

Fig. 6. Distribution of the normalized mean absolute error based on daily values of predicted and measured albedo over alfalfa.

solar irradiance were less than $200 \mathrm{~W} \mathrm{~m}^{-2}$ and the incoming solar irradiance was composed of only the diffuse component. To illustrate differences between the period prior to DOY 161 and that following, measured hourly values of incoming solar irradiance and modeled direct beam fraction for DOY 158 and 165 are given in Fig. 7. From 0800-1300 the magnitude of the incoming solar radiation on DOY 158 was such that the direct beam fraction was zero. In comparison, DOY 165 was a clear, sunny day. Thus, under conditions when the diffuse component of the incoming solar irradiance predominates, the model does not predict as well as when the direct beam predominates. Evaluating the daily average (0800-1800) direct beam fraction in terms of the NMAE, for the albedo predictions during both regrowth cycles, shows the general trend of higher NMAE values when diffuse light predominates and lower values as the direct beam fraction increases, Fig. 8.

Other periods where relatively high values of NMAE occurred, DOY 169-172 and DOY 186-191 coincide with rain events, low LAIs, and overcast and/or foggy conditions. The formation and duration of water droplets on leaf surfaces may have affected leaf optical properties; this condition was not evaluated in the determination 

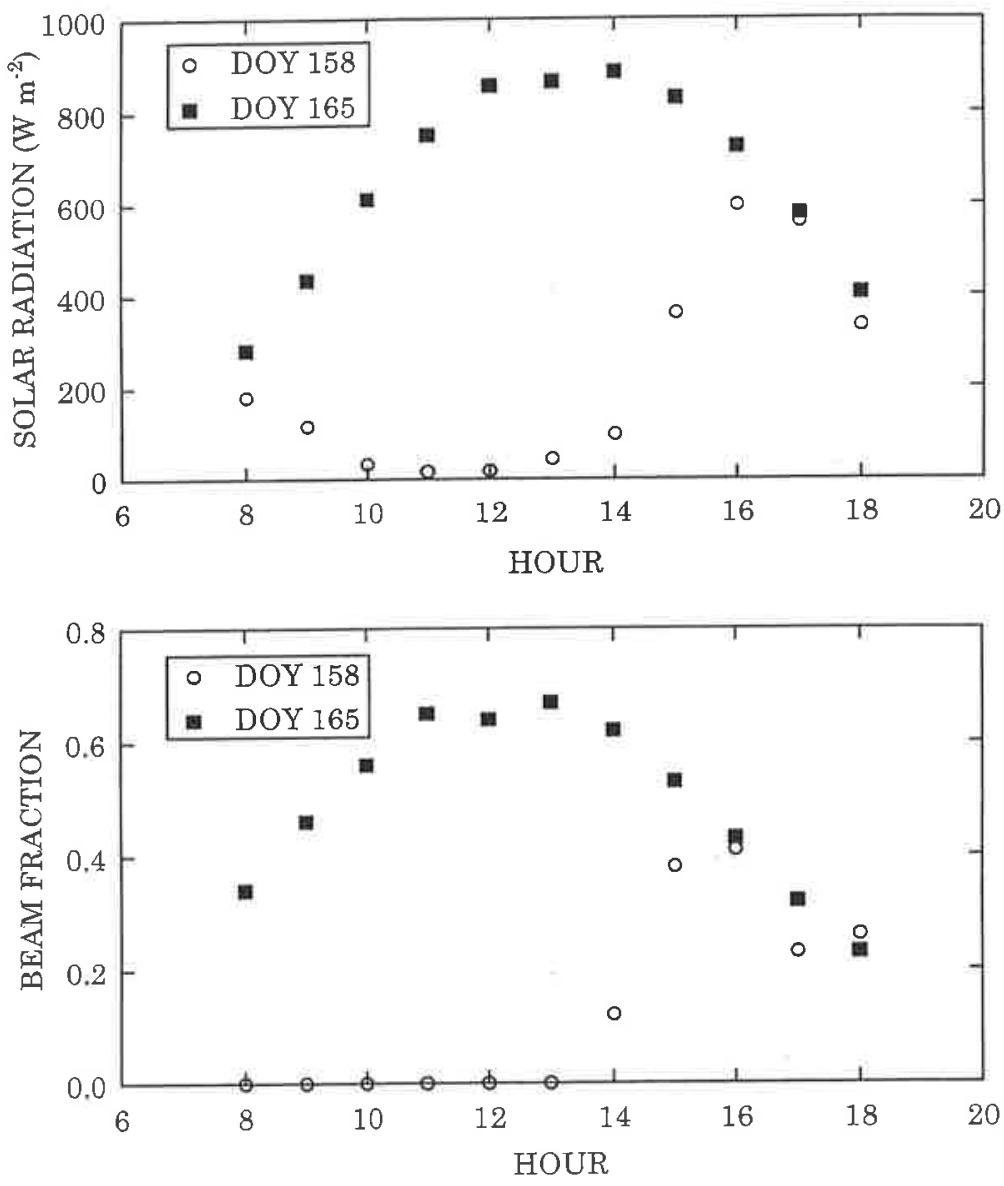

Fig. 7. Comparison of measured incoming solar radiation (upper) and modeled direct beam fraction (lower) for DOY $158(\mathrm{NMAE}=0.21)$ and DOY $165(\mathrm{NMAE}=0.015)$.

of leaf optical properties, nor is it included in the model. Also, at the beginning of each regrowth cycle, the NMAE values were relatively high. Although rainfall could explain these results, it is possible that low LAI values in combination with reflectance from the soil and plant residue could also have been important factors.

\section{Conclusions}

An empirical relationship, based on an albedo model that used a spherical leaf angle distribution, was developed to predict hourly and daily values of albedo of two heliotropic crops, alfalfa and soybean. The model performed well under a wide variety of sky conditions. However, the model did not perform as well under very overcast skies when incoming irradiance was comprised totally of diffuse radiation, 


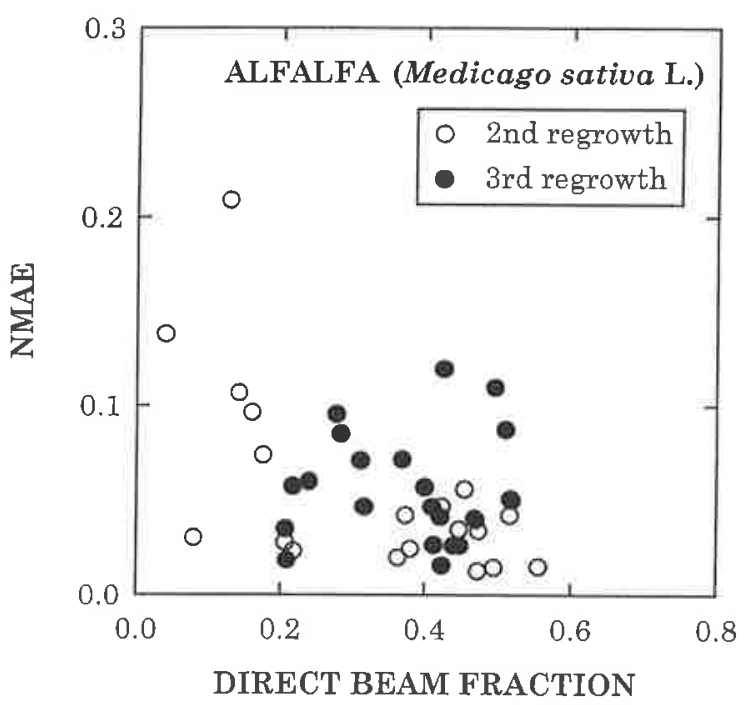

Fig. 8. Daily average (0800-1800) direct beam fraction of the incoming solar radiation versus normalized mean absolute error for alfalfa for both cutting periods, excluding the day used for calibration purposes.

possibly when water droplets affected leaf optical properties, nor under low LAI conditions, when soil and plant residue contributed to measured albedo.

When leaf optical properties changed, as in the soybean, the model predicted quite well under a wide range of LAI and wide swings in single leaf PAR reflectance and transmittance. Thus, for these two crops (alfalfa and soybean), the empirical relationships developed here can be used with confidence to predict albedo when the LAI $>1.0$. This algorithm may be used in modifying existing crop simulation models that deal with heliotropic canopies as well as in the development of new crop models.

Appendix. Variable definitions

\begin{tabular}{lll}
\hline Symbol & Definition & Units \\
\hline$A^{\prime}$ & limit of albedo as LAI becomes very large & - \\
$\mathrm{AL}$ & leaf reflectivity & - \\
$A_{\mathrm{CPY}}$ & albedo of the canopy & - \\
$A_{\mathrm{DIF}}$ & albedo associated with diffuse radiation & - \\
$A_{\mathrm{DIR}}$ & albedo associated with direct beam & - \\
$A_{\mathrm{HOR}}$ & albedo for horizontal leaves & - \\
$A_{\mathrm{S}}$ & albedo of soil surface & - \\
$A_{\mathrm{SOL}}$ & first estimate of albedo assuming equal contributions & - \\
& from the PAR and NIR bands
\end{tabular}

(Table continued on next page) 
Table (continued)

\begin{tabular}{lll}
\hline Symbol & Definition & Units \\
\hline LAI & leaf area index & $\mathrm{m}^{2} \mathrm{~m}^{-2}$ \\
NIR & near infrared radiation $(700-3000 \mathrm{~nm})$ & $\mathrm{MJ} \mathrm{m}^{-2} \mathrm{day}^{-1}$ \\
PAR & photosynthetically active radiation $(400-700 \mathrm{~nm})$ & $\mathrm{MJ} \mathrm{m}^{-2} \mathrm{day}^{-1}$ \\
TL & leaf transmissivity & - \\
$a$ & extinction coefficient & - \\
$f$ & direct beam fraction of incoming radiation & - \\
$h$ & solar elevation angle & degrees \\
\hline
\end{tabular}

\section{References}

Cornell, D., 1991. Sun-View-Target Effects on Remotely-Derived Spectral Indices Estimates of Absorbed Radiation and Leaf Area. MS thesis, University of Nebraska-Lincoln.

Dedieu, G., Deschamps, P.Y., Kerr, Y.H., 1987. Satellite estimation of solar irradiance at the surface of the earth and of surface albedo using a physical model applied to Meteosat data. J. Clim. Appl. Meteorol. 26, 79-87.

Duffett-Smith, P., 1990. Astronomy with your Personal Computer. Cambridge University Press, Cambridge.

Dvoracek, M.J., Hannabas, B., 1990. Prediction of albedo for use in evapotranspiration and irrigation scheduling. In: Visions of the Future. ASAE, St. Joseph, MI, pp. 692-699.

Goudriaan, J., 1977. Crop Micrometeorology: a Simulation Study. Pudoc, Wageningen.

Jacobs, A.F.G., van Pul, W.A.J., 1990. Seasonal changes in the albedo of a maize crop during two seasons. Agric. For. Meteorol. 49, 1351-1360.

Janssen, P.H.M., Heuberger, P.S.C., 1995. Calibration of process-oriented models. Ecol. Modelling 83, 55-66.

Meyer, W.S., Walker, S., 1981. Leaflet orientation in water-stressed soybeans. Agron. J. 73, 1071-1074.

Moran, M.S., Pinter Jr., P.J., Clothier, B.E., Allen, S.G., 1989. Effect of water stress on the canopy architecture and spectral indices of irrigated alfalfa. Remote Sens. Environ. 29, 251-261.

Unkasevic, M., 1989. Some improvements in calculating the plant stand surface albedo and its influence on ground surface temperature. Int. J. Biometeorol. 33, 184-195.

Walter-Shea, E.A., 1993. Sensitivity of the relationship between FAPAR and vegetative indices to sunview geometry, USDA-ARS US Water Conservation Laboratory on Remote Sensing of Soils and Vegetation at Phoenix, AZ, January 6-8, pp. 19.

Walter-Shea, E.A., Privette, J.L., Cornell, D., Mesarch, M.A., Hays, C.J., 1997. Relations between directional spectral vegetation indices and leaf area and absorbed radiation in alfalfa. Remote Sensing of Environment 61, 162-177.

Weiss, A., Norman, J.M., 1985. Partitioning solar radiation into direct and diffuse, visible and nearinfrared components. Agric. For. Meteorol. 34, 205-213. 